\title{
Влияние режимов электрохимического травления на морфологию, структурные и оптические свойства пористого арсенида галлия
}

\author{
(С) П.В. Середин ${ }^{1}$, А.С. Леньшин ${ }^{1}$, А.В. Федюкин ${ }^{1}$, Д.Л. Голощапов ${ }^{1}$, А.Н. Лукин ${ }^{1}$, \\ И.Н. Арсентьев ${ }^{2}$, А.В. Жаботинский ${ }^{2}$ \\ ${ }^{1}$ Воронежский государственный университет, \\ 394006 Воронеж, Россия \\ ${ }^{2}$ Физико-технический институт им. А.Ф. Иоффе Российской академии наук, \\ 194021 Санкт-Петербург, Россия \\ E-mail: paul@phys.vsu.ru
}

(Получена 5 июня 2017 г. Принята к печати 27 ноября 2017 г.)

\begin{abstract}
Методами рентгеновской дифракции, электронной микроскопии, инфракрасной и ультрафиолетовой спектроскопии в работе изучены свойства образцов пористого $\mathrm{GaAs}$, полученного методом электрохимического травления монокристаллических пластин $n-\mathrm{GaAs}(100)$. Удалось показать, что подбором состава электролита и условий травления могут быть получены образцы не только с различной степенью пористости и размером пор (нано/микро), но и иным типом поверхности образца. Травление $n$-GaAs(100) в выбранных условиях не приводит к изменению ориентации пористого слоя относительно ориентации монокристаллической подложки $\mathrm{GaAs}(100)$, ведет к уменьшению полуширины дифракционного максимума по сравнению с исходной пластиной, приводит к расщеплению фононной моды в инфракрасных спектрах и частотному сдвигу компонент с учетом параметров анодного травления, а также меняет оптические свойства в ультрафиолетовом диапазоне.
\end{abstract}

DOI: 10.21883/FTP.2018.09.46231.8659

\section{1. Введение}

В последние десятилетия протестировано множество способов получения пористых полупроводниковых структур, среди которых электрохимическое анодное травление является наиболее универсальным из разработанных [1-3]. Его особенности, такие как низкая температура, простота и дешевизна использования, делают его максимально привлекательным для создания нанокристаллических пористых материалов на основе кремния, бинарных полупроводников $\mathrm{A}^{\mathrm{III}} \mathrm{B}^{\mathrm{VI}}$ и твердых растворов на их основе [4-6]. Электрохимически сформированные пористые наноструктуры на основе GaAs являются весьма привлекательными материалами для широкого круга приложений [7], что подтверждается уже известными литературными данными [8]. В последнее время нанопористые слои GaAs активно используются для создания переходного буферного слоя с пониженными коэффициентами упругости при создании гетероструктур с большим рассогласованием параметров решетки у гетеропары. Не менее актуально применение пористого слоя $\mathrm{GaAs}$ для создания просветляющих покрытий солнечных элементов [2,7].

Хорошо известно, что подбором конкретного состава электролита, конфигурации ячейки электрохимического травления и рабочих характеристик процесса можно получить необходимые параметры для пористых слоев GaAs. Однако при всем этом качество получаемых на сегодняшний день пористых слоев GaAs весьма далеко от совершенства и не всегда пригодно для дальнейшей эпитаксии. Хорошо известно, что при электрохимическом травлении $n$-GaAs плотность пор, их размеры, а также структура пористого слоя весьма сильно зависят от плотности легирования и кристаллографической ориентации исходной пластины. Поэтому развитие технологии получения и исследования структурного и оптического качества пористого слоя GaAs в зависимости от состава электролита является существенным фактором для достижения успеха.

Таким образом, цель нашей работы заключалась в исследовании методами рентгеновской дифракции, электронной микроскопии, ИК и УФ спектроскопии свойств пористого GaAs, полученного методом электрохимического травления монокристаллических пластин.

\section{2. Материалы и методы исследования}

Подложкой являлся зеркально полированный с обеих сторон GaAs $n$-типа, легированный $\mathrm{Si} n=10^{18} \mathrm{~cm}^{-3}$. Перед процессом электрохимического травления образцы помещались в ультразвуковую ванну, где происходило их обезжиривание в ацетоне, изопропаноле и этаноле, после чего образцы были промыты дистиллированной водой. Далее мы удалили естественный оксидный слой на поверхности пластины GaAs, для чего было выполнено травление в растворах $\mathrm{NH}_{4} \mathrm{OH}: \mathrm{H}_{2} \mathrm{O}_{2}: \mathrm{H}_{2} \mathrm{O}$ $(1: 1: 10), \quad \mathrm{HCl}: \mathrm{H}_{2} \mathrm{O}_{2}: \mathrm{H}_{2} \mathrm{O} \quad(1: 1: 20), \mathrm{NH}_{4} \mathrm{OH}: \mathrm{H}_{2} \mathrm{O}$ $(1: 5)$ в течение 30,100 и 30 с соответственно.

Формирование пористого слоя на обработанных пластинах $\mathrm{GaAs}$ было выполнено с использованием разработанной нами ячейки электрохимического травления с оригинальной формой электрода, которая обеспечивает равномерное распределение поля по поверхности пластины, чем достигается однородность морфологии и ха- 
рактеристик образца по поверхности. Состав электролита для первой части эксперимента: $\mathrm{HF}: \mathrm{C}_{3} \mathrm{H}_{7} \mathrm{OH}=1: 4$. Плотность тока, подаваемого на электроды, изменялась в пределах $25-100 \mathrm{MA} / \mathrm{cm}^{2}$. Для второй части эксперимента был выбран следующий состав электролита: $\mathrm{HF}: \mathrm{C}_{3} \mathrm{H}_{7} \mathrm{OH}=1: 6$. Пределы плотности тока $25-75 \mathrm{MA} / \mathrm{cm}^{2}$.

Диагностику полученных пористых слоев GaAs проводили методами рентгеновской дифракции, с использованием дифрактометра ДРОН 4-07 с кобальтовой трубкой. Исследования качества поверхности образцов были выполнены на электронном микроскопе Libra 120 Carl Zeiss. ИК-спектры отражения в области фононного резонанса GaAs были получены с использованием ИК фурье-спектрометра Vertex-70 Bruker, оснащенного приставкой на отражение с изменяемым углом падения излучения в широком диапазоне. Оптические свойства образцов изучались в диапазоне $190-900$ нм, методом УФ-спектроскопии, с помощью прибора LAMBDA 650 фирмы Perkin Elmer, оснащенного универсальной приставкой URA, позволяющей получать спектры отражения в интервале углов падения от 8 до $80^{\circ}$. При этом рабочая схема приставки позволяет получать абсолютное отражение. Спектры отражения нами были получены при угле падения $67^{\circ}$. Для регистрации спектров фотолюминесценции пористого слоя был использован усовершенствованный волоконно-оптический спектрометр USB4000-VIS-NIR (Ocean Optics), сопряженный с компьютером. Предложенное техническое решение по модернизации оптической схемы устройства позволило существенно снизить потери сигнала люминесценции при передаче его в спектрометр и исключить частотнозависимые потери. В качестве источников возбуждения фотолюминесценции использовался лазерный модуль с максимумом излучения в области 532 нм. Плотность мощности излучения не превышала $20 \mathrm{MBT} / \mathrm{cm}^{2}$. Временно́е разрешение устройства определялось разрешением спектрометра и составляло величину 3.8 мс. Для вырезания длинноволновой области излучения лазерных диодов, а также для выделения излучения флуоресценции использовались соответствующие интерференционные светофильтры (ThorLabs).

\section{3. Полученные результаты}

Как уже было отмечено выше, подбор условий анодного травления, таких как состав электролита и плотность тока, подаваемая на электроды для получения равномерно травленого слоя GaAs c различной степенью пористости, стал основной задачей нашего исследования. Для первой части эксперимента мы использовали состав электролита $\mathrm{HF}: \mathrm{C}_{3} \mathrm{H}_{7} \mathrm{OH}=1: 4$. Данный состав электролита привлек наше внимание своей доступностью. Кроме того, уже было показано [5], что с помощью такого состава электролита можно получить нанопористые слои GaAs. Плотность тока, подаваемого на электроды,

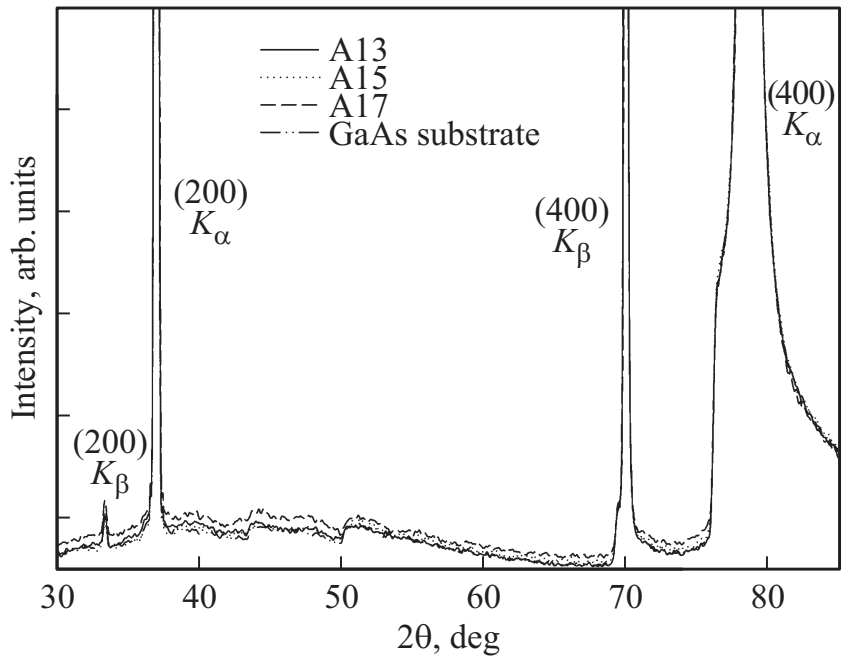

Рис. 1. Результаты рентгеновской дифрактометрии.

изменялась в пределах $25-100 \mathrm{MA} / \mathrm{cm}^{2}$. Следует отметить, что при увеличении времени электрохимического травления на поверхности образцов образуется темная пленка, а при увеличении плотности тока $J \geq 50 \mathrm{MA} / \mathrm{cm}^{2}$ возможно образование толстого пористого слоя, легко отделяющегося от подложки. При $J=100 \mathrm{MA} / \mathrm{cm}^{2}$ этот слой рассыпается в порошок еще в процессе травления. Обнаруженные нами процессы подобны тем, что описывали авторы из работы [6], хотя составы используемых электролитов отличаются.

Во второй части эксперимента мы изменили состав электролита, а именно увеличили долю спирта в составе электролита. Состав электролита стал $\mathrm{HF}: \mathrm{C}_{3} \mathrm{H}_{7} \mathrm{OH}=1: 6$. Пределы плотности тока изменили, снизив верхний до $75 \mathrm{~mA} / \mathrm{cm}^{2}$. Такие изменения позволили заметно (в разы) уменьшить эрозию поверхности, а также получить новый и оптимальный результат травления.

По итогам экспериментов мы отобрали для исследований наиболее перспективные образцы, условия формирования которых представлены в табл. 1 .

После синтеза образцов для определения фазового состава, а также структурного качества полученного слоя мы исследовали данные материалы методом рентгеновской дифракции. На рис. 1 представлены обзорные дифрактограммы полученных образцов, а также монокристаллической подложки GaAs. Как видно из полученных данных, на дифрактограммах всех образцов

Таблица 1. Условия получения образцов

\begin{tabular}{c|c|c}
\hline № образца & $\begin{array}{c}\text { Плотность } \\
\text { силы тока, мA/см² }\end{array}$ & $\begin{array}{c}\text { Состав электролита } \\
\mathrm{HF}: \mathrm{C}_{3} \mathrm{H}_{7} \mathrm{OH}\end{array}$ \\
\hline A13 & 25 & $1: 4$ \\
A15 & 75 & $1: 4$ \\
A17 & $25-75$ & $1: 6$
\end{tabular}


присутствуют лишь дифракционные рефлексы (200), (400), характерные для дифракции монокристаллического GaAs с ориентацией (100). Во-первых, этот факт свидетельствует о том, что при выбранных условиях травления не образуется пористый поликристаллический слой, что в основном характерно при аналогичных процессах формирования пористого кремния [9,10], во-вторых, экспериментальные данные показывают, что слой, полученный анодным травлением, имеет ту же самую кристаллографическую ориентацию (100), что и у монокристаллической подложки GaAs. Оценить структурное качество у сформированного пористого слоя GaAs мы смогли путем анализа $K_{\alpha 1}$-линии рефлекса (600) GaAs, расположенного в области далеких углов $\left(2 \Theta \sim 143^{\circ}\right)$. На рис. 2 приведены профили этих линий для монокристаллической подложки и образцов с пористым слоем. Анализ полуширины (600) $K_{\alpha 1}$-рефлекса показывает (см. табл. 2), что получение пористого слоя не приводит к ухудшению структурного качества образца. Напротив, увеличение плотности тока при травлении, а также подбор состава электролита приводят к уменьшению

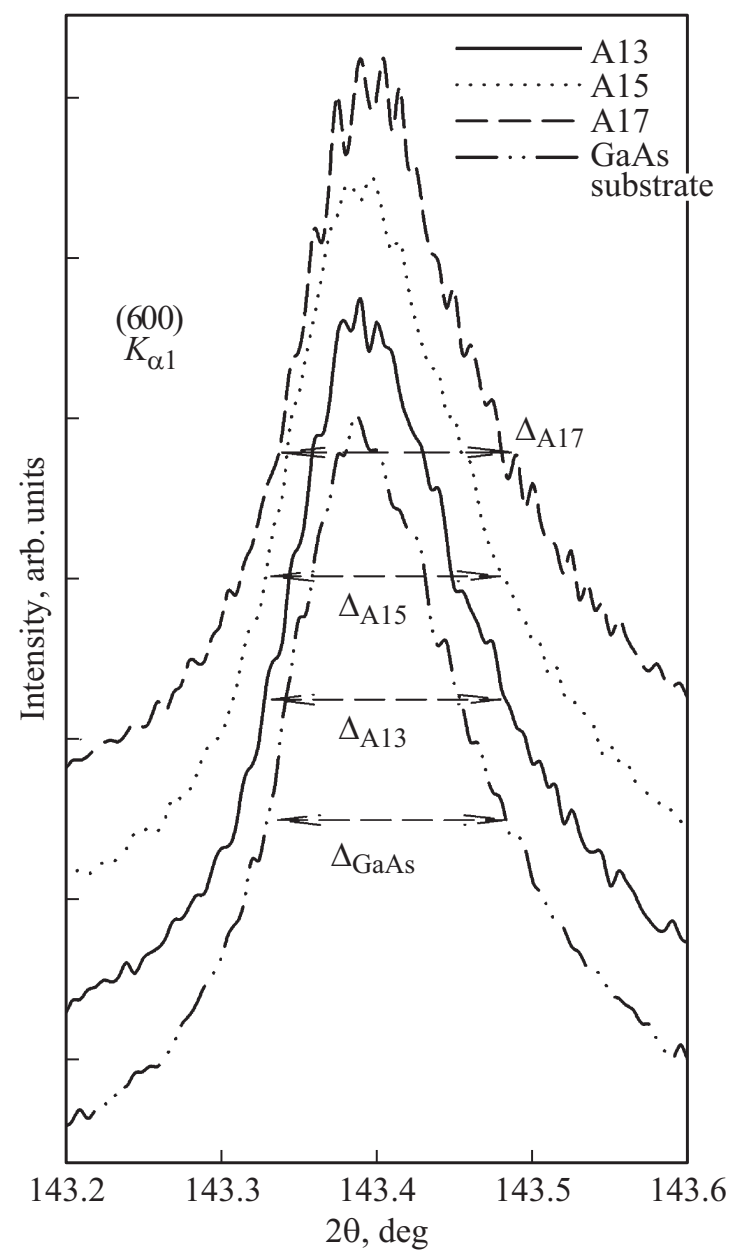

Рис. 2. Дифракционные профили $K_{\alpha 1}$-рефлексов (600) отражения для монокристаллической подложки и образцов с пористым слоем.
Таблица 2. Результаты рентгеновской дифракции

\begin{tabular}{c|c}
\hline Образец & Полуширина, град. \\
\hline GaАs-подложка & $\Delta_{\text {GaAs }}=0.152$ \\
A13 & $\Delta_{\mathrm{A} 13}=0.146$ \\
$\mathrm{~A} 15$ & $\Delta_{\mathrm{A} 15}=0.137$ \\
$\mathrm{~A} 17$ & $\Delta_{\mathrm{A} 17}=0.137$
\end{tabular}

полуширины дифракционного максимума по сравнению с аналогичной величиной у монокристаллической подложки. Этот факт является результатом вытравливания дефектных областей в монокристаллической пластине.

Исследования процессов порообразования и морфологии поверхности полученных нами образцов por- $n$-GaAs были выполнены нами с привлечением растровой электронной микроскопии. На рис. 3 приведены микрофотографии с участками пористого слоя/сколы для исследованных нами образцов. Так, на рис. 3, $a$ представлена морфология поверхности образца А13. Из рисунка видно, что выбранные условия анодного травления позволяют получить пористый слой толщиной до 10 мкм и выраженными углублениями на поверхности диаметрами до 1 мкм и системой мелких пор в объеме пористого слоя. В то же время увеличение силы тока в процессе травления дает возможность сформировать более выраженный нанопористый слой у $n$-GaAs, с системой пор перпендикулярно поверхности, как это имеет место в случае образца А 15 , скол которого приведен на рис. $3, b$. Полученный тип нанопористого GaAs по своей структуре и морфологии аналогичен тому, который был сформирован нами при анодном травлении $\mathrm{Si}$ [11]. Не менее интересным представляется результат, полученный нами на втором этапе эксперимента и представленный на рис. 3,c. Подбор условий анодного травления позволил сформировать на поверхности пластин GaAs правильные многогранники монокристаллического GaAs, расположенные на сопоставимых друг от друга расстояниях с одинаковой плотностью на единицу поверхности (рис. 3,c).

Для изучения тонких решеточных свойств и оценки структурного качества пористых слоев мы привлекли ИК-спектроскопию отражения, позволяющую дать заключение не только о составе вещества, но и о внутренних напряжениях в его решетке, к которым данный метод является очень чувствительным $[12,13]$. Как видно из эксперимента, в спектрах всех образцов присутствует лишь высокоинтенсивная колебательная мода, соответствующая колебаниям $\mathrm{Ga}-\mathrm{As}$. Кроме того, в спектрах отражения образцов с пористым слоем появляются слабоинтенсивные колебательные моды, локализованные в двух областях (см. рис. 4). Так, поперечные колебания, расположенные около $335-315 \mathrm{~cm}^{-1}$, отчетливо заметные в спектрах образцов А15 и A17, вероятнее всего, принадлежат колебаниям оксидам $\mathrm{Ga}_{x} \mathrm{O}_{y}$, образующимся в результате травления исходной монокри- 


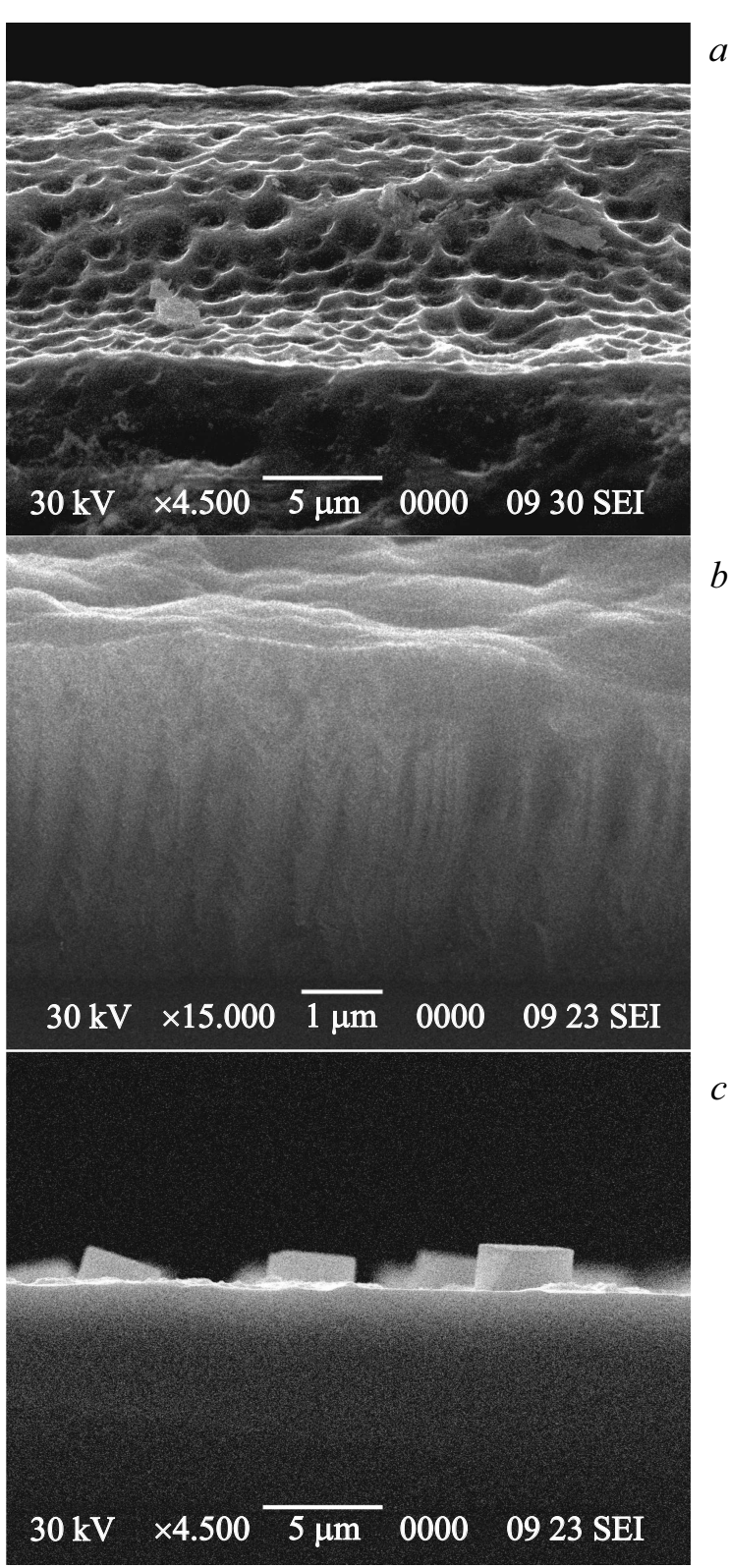

Рис. 3. Результаты сканирующей электронной микроскопии сколов образцов, полученных методом анодного травления $\operatorname{GaAs}(100): a$ - образец А13, $b$ - образец А15, $c$ - образец А17.

сталлической пластины, что соответствует данным из работы [14]. Что касается области $220-215 \mathrm{~cm}^{-1}$, в которой у образца А17, полученного на втором этапе эксперимента, присутствует низкоинтенсивное колебание, то в соответствии с данными работы [15] его появление является следствием образования тонкого аморфного слоя $a$-GaAs в результате анодного травления пластины $n-\operatorname{GaAs}(100)$.

Анализ полученных экспериментальных данных показывает, что форма основного фононного колебания от монокристаллического GaAs (см. рис. 4), а также определенные частоты продольного $\omega_{\mathrm{LO}}=291 \mathrm{~cm}^{-1}$ и поперечного $\omega_{\text {Tо }}=267 \mathrm{~cm}^{-1}$ фононов совпадают с известными литературными данными [16,17], а также результатами наших предыдущих работ $[18,19]$. В случае образцов с пористым слоем форма фононного спектра претерпевает изменение. В спектре отражения хорошо заметно не только расщепление фононной моды на компоненты $\mathrm{TO}_{1 \mathrm{Ga}-\mathrm{As}}$ и $\mathrm{TO}_{2 \mathrm{Ga}-\mathrm{As}}$, но и частотный сдвиг этих компонент с учетом параметров анодного травления. Следует отметить, что величина расщепления фононной моды на компоненты коррелирует с данными рентгеновской дифракции, а именно с величиной полуширины дифракционного максимума (600) $K_{\alpha 1}$-рефлекса. Хорошо видно, что с увеличением величины расщепления фононной моды уменьшается величина (600) $K_{\alpha 1}$-рефлекса. Наиболее вероятной причиной появления отдельных колебаний в ИК-спектре отражения является локализация оптических фононов в слое, созданном в результате анодного травления по аналогии с тем, как это происходит в случае сверхрешеток [20].

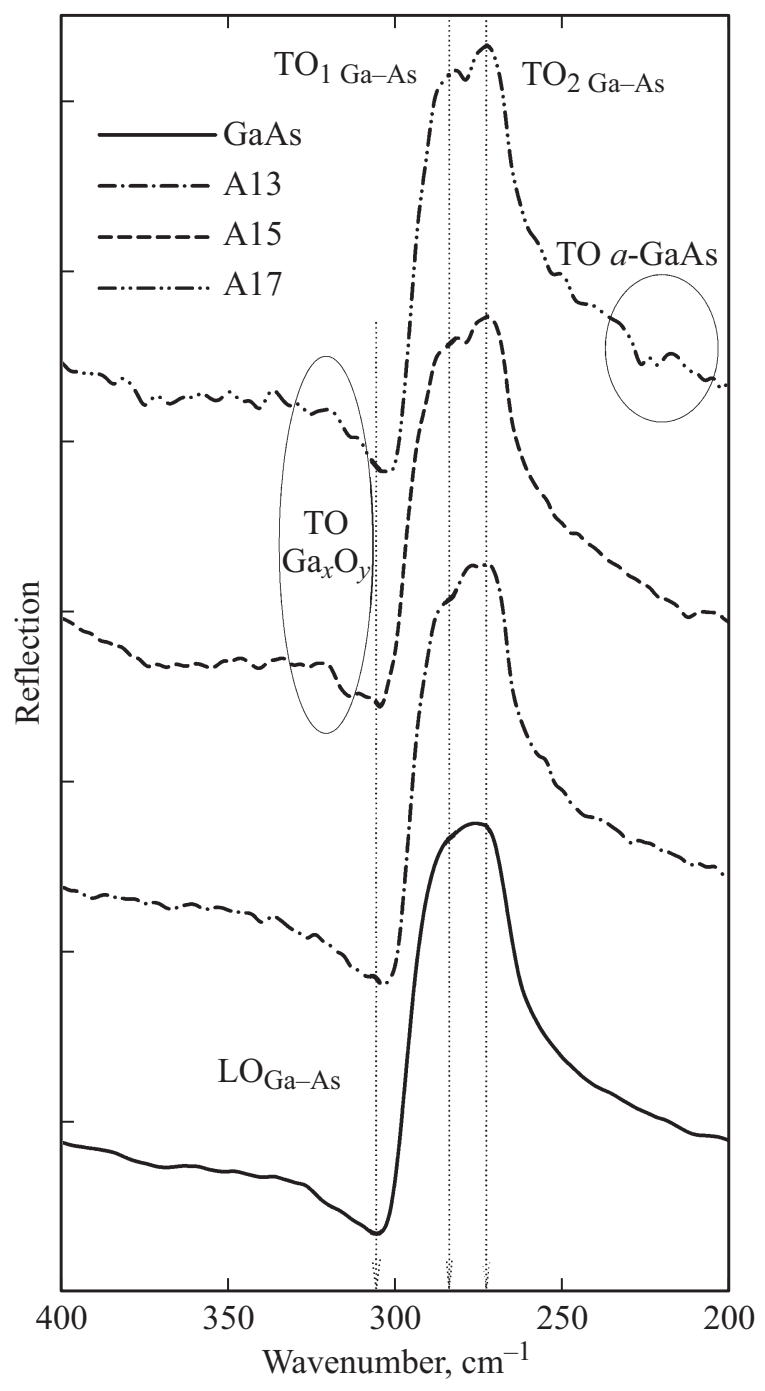

Рис. 4. ИК-спектры отражения в области фононного резонанса для структур, полученных методом анодного травления, и подложки $\mathrm{GaAs}(100)$. 

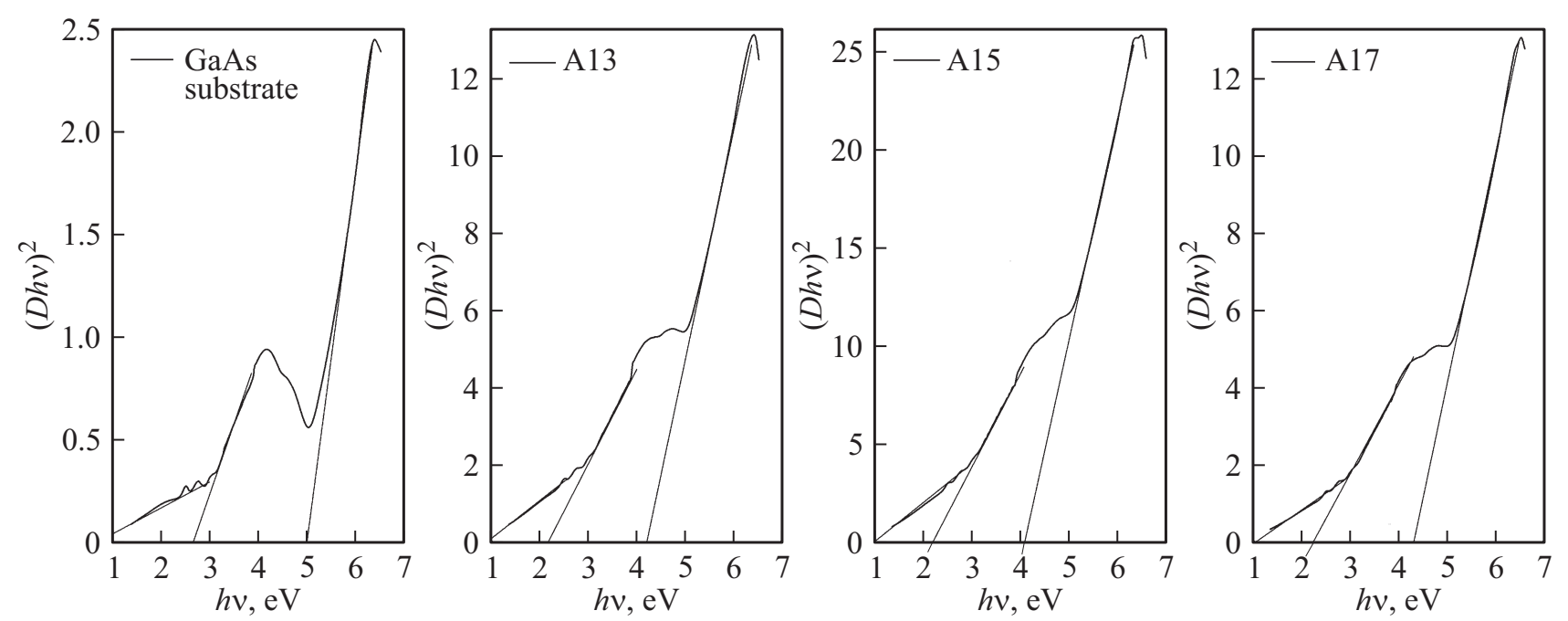

Рис. 5. Зависимости $(D \cdot h v)^{2}$ от энергии квантов для структур, полученных методом анодного травления, и подложки GaAs(100).

Для изучения оптических свойств в УФ-диапазоне у сформированных методом анодного травлении слоев мы использовали отработанный нами подход с применением методики съемки на отражение [21-23]. Эта методика позволяет получить информацию от пленок/слоев, нанесенных/сформированных на оптически более плотных и объемных подложках.

Спектры пропускания-отражения исследованных образцов были получены при угле падения электромагнитного излучения $45^{\circ}$ в области $190-900$ нм. С целью выявления механизмов оптического поглощения в слоях, сформированных методом электрохимического травления с использованием возможностей программы OPUS Bruker и учетом формулы Ламберта-Бугера: $T=\exp [-D]$, где $T-$ пропускание, $D-$ оптическая плотность, мы перестроили спектры пропускания-отражения в спектры поглощения.

На рис. 5 представлены зависимости $(D \cdot h v)^{2}$ от энергии квантов для монокристалличекого GaAs, а также образцов, полученных методом электрохимического травления, которые были рассчитаны из спектра зеркального отражения с использованием соотношений Крамерса-Кронига [24].

Графический анализ зависимостей $(D \cdot h v)^{2}$ от энергии квантов позволил выявить отдельные участки графиков (рис. 5) с линейной зависимостью, что может указывать на наличие в заданной спектральной области прямых разрешенных переходов (рис. 5). Линейная экстраполяция данных участков к нулевому значению позволяет определить энергию прямых переходов, характерных для образцов. В табл. 3 приведены энергии переходов для исследованных в работе образцов, определенные по вышеописанной методике.

Анализируя полученные результаты, а также известные литературные данные [25], можно говорить о том, что в спектре монокристаллической подложки наблюдаются два прямых перехода с энергиями 2.90 и 5.03 эВ, первый из которых соответствует переходу $\Lambda_{3} \rightarrow \Lambda_{1}$, а второй - высокоэнергетический, $X_{5} \rightarrow X_{1}$. Что касается спектров образцов с пористым слоем, полученным анодным травлением исходной пластины, то в их спектрах присутствуют также два перехода с энергиями $\sim 2.2$ и $\sim 4.15$ эВ, которые в соответствии с литературными данными [25] относятся к прямым переходам из валентной зоны в зону проводимости $\Gamma_{15} \rightarrow \Gamma_{15}$ и $L_{3} \rightarrow L_{1}$. Хорошо видно, что анодное травление $n$-GaAs приводит к иным, нежели в случае с исходным монокристаллическим $n$-GaAs, оптическим свойствам в УФ-диапазоне.

Хорошо известно, что изменение стехиометрии в слое пористого арсенида галлия, полученного методом электрохимического травления, должно отразиться на его энергетических характеристиках, т.е. на спектрах фотолюминесценции. Привлечение метода фотолюминесцентной спектроскопии для анализа электронной структуры материалов, определения ширины запрещенной зоны, исследования примесных уровней, а также изучения механизмов рекомбинации и определения качества материалов кажется нам наиболее оптимальным.

Таблица 3. Энергия прямых межзонных переходов в спектрах образцов

\begin{tabular}{c|c|c}
\hline № образца & \multicolumn{2}{|c}{ Тип и энергия перехода, эВ } \\
\hline \multirow{2}{*}{ GaAs-подложка } & $\Lambda_{3} \rightarrow \Lambda_{1}$ & $X_{5} \rightarrow X_{1}$ \\
& 2.90 эB & 5.03 эB \\
A13 & $\Gamma_{15} \rightarrow \Gamma_{15}$ & $L_{3} \rightarrow L_{1}$ \\
& 2.20 эB & 4.25 э \\
A15 & $\Gamma_{15} \rightarrow \Gamma_{15}$ & $L_{3} \rightarrow L_{1}$ \\
& 2.20 эB & 4.05 эB \\
A17 & $\Gamma_{15} \rightarrow \Gamma_{15}$ & $L_{3} \rightarrow L_{1}$ \\
& 2.20 э & 4.03 э
\end{tabular}



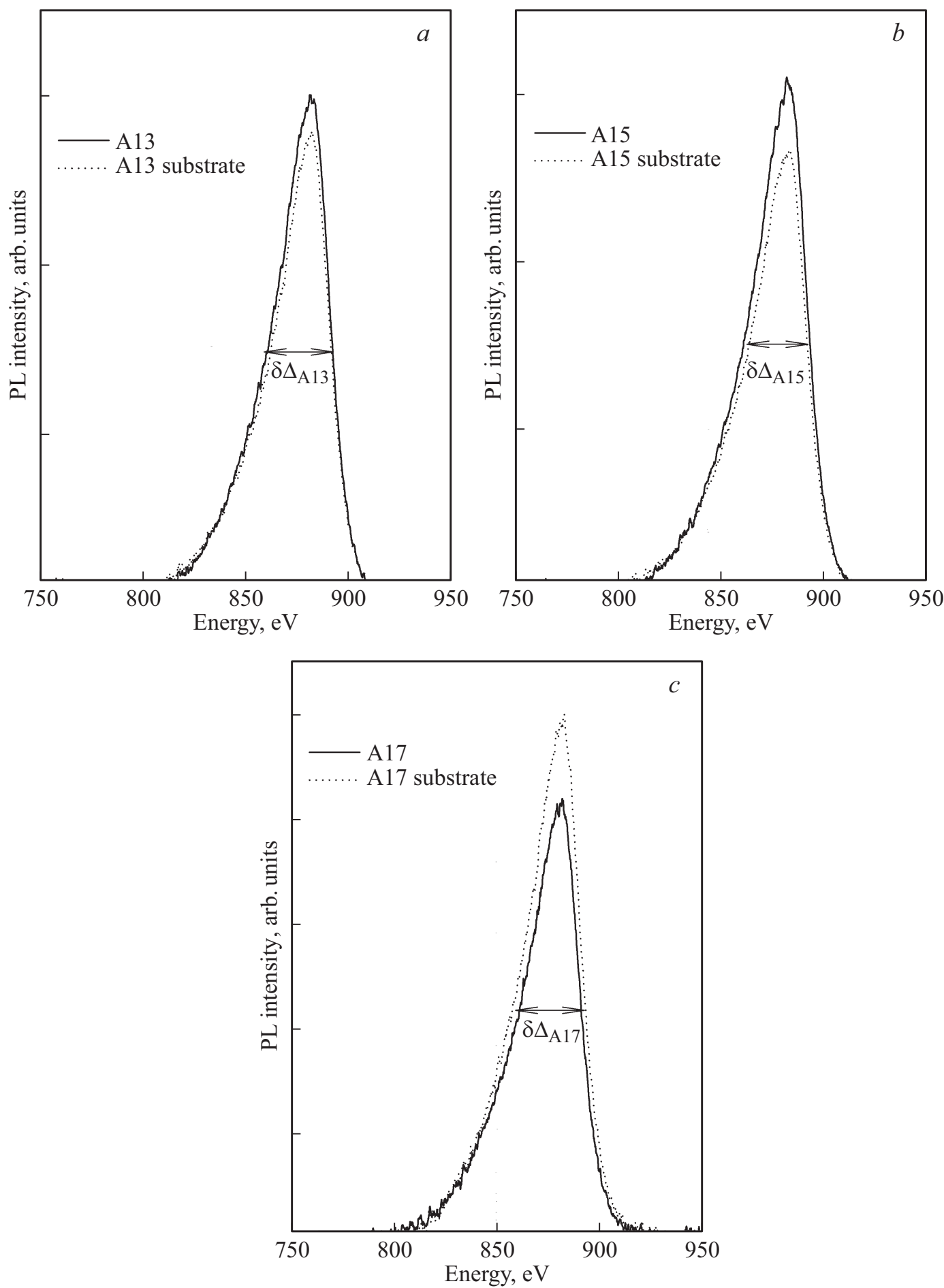

Pис. 6. Спектры фотолюминесценции структур, полученных методом анодного травления, в сравнении со спектром пластины $\operatorname{GaAs}(100)$, использованной при получении образцов.

На рис. 6 представлены спектры фотолюминесценции, полученные от исследуемых в работе образцов, а также монокристаллической подложки $\operatorname{GaAs}(100)$, использованной для их создания. Спектры получены при комнатной температуре, в идентичных условиях и приведены на графике без нормировки. Из полученных экспериментальных результатов видно, что в спектрах всех образцов присутствует один эмиссионный пик с энергией $\sim 1.43$ эВ, соответствующий переходу зоназона в GaAs. Однако заметно, что интенсивность фотолюминесценции от слоя, полученного анодным травлением, зависит от условий получения образца. Так, эксперимент показывает, что в случае получения микропористого и нанопористого слоев GaAs интенсивность 
полосы фотолюминесценции возрастает при незначительном $\left(\delta \Delta A_{13} \sim 1.5 \mathrm{Hм}, \delta \Delta A_{15} \sim 1.5 \mathrm{Hм}\right)$ уменьшении полуширины пика фотолюминесценции. При этом в случае нанопористого арсенида галлия эмиссия возрастает более чем на $20 \%$ по сравнению с фотолюминесценцией от исходной пластины. Наблюдаемое изменение в спектрах фотолюминесценции образцов с пористым слоем связано с уменышением поглощения на свободных носителях заряда (электронах), число которых в поверхностном пористом слое уменьшается, и уменьшением поверхностной рекомбинации в пористом слое.

При этом следует обратить внимание на спектры фотолюминесценции образца А17, на поверхности которого методом электрохимического травления были сформированы правильные многогранники монокристаллического GaAs. Для этого образца интенсивность фотолюминесценции заметно ниже $(\sim 19 \%)$ по сравнению с фотолюминесценцией от исходной пластины $\mathrm{GaAs}(100)$. Скорее всего, этот факт является следствие образования на поверхности данного образца аморфного слоя $a$-GaAs, а также оксидной фазы $\mathrm{Ga}_{x} \mathrm{O}_{y}$, которые ответственны за усиление процессов безызлучательной рекомбинации.

\section{4. Заключение}

Методами рентгеновской дифракции, электронной микроскопии, ИК- и УФ-спектроскопии в работе изучены свойства образцов пористого GaAs, полученного методом электрохимического травления монокристаллических пластин $n$-GaAs(100). Удалось показать, что подбором состава электролита и условий травления могут быть получены образы не только с различной степенью пористости и размером пор (нано/микро), но и иным типом поверхности образца. Увеличение массовой доли спирта в составе электролита, а также снижение тока в ячейке травления позволило заметно (в разы) уменьшить эрозию поверхности, а также получить на поверхности пластин правильные многогранники монокристаллического GaAs. Травление $n$ - $\mathrm{GaAs}(100)$ в выбранных условиях не приводит к изменению ориентации пористого слоя относительно ориентации монокристаллической подложки $\mathrm{GaAs}(100)$, ведет к уменьшению полуширины дифракционного максимума по сравнению с исходной пластиной, приводит к расщеплению фононной моды в ИК-спектрах и частотному сдвигу компонент с учетом параметров анодного травления, а также меняет оптические свойства в УФ-диапазоне. Условия электрохимического анодного травления влияют на интенсивность полосы фотолюминесценции образца, позволяя увеличить выход люминесценции более чем на $20 \%$.

Полученные данные могут быть использованы с целью развития технологии получения пористого слоя GaAs c заданными структурными, морфологическими и оптическими свойствами.
Работа выполнена при поддержке гранта Президента РФ МД-188.2017.2. В части диагностики пористых структур работа поддержана грантом № 11.4718.2017/8.9 Министерства образования и науки России в рамках государственного задания вузам в сфере научной деятельности на 2017-2019 г.

В части управления морфологией, составом поверхности и функциональными характеристиками низкоразмерных систем исследование выполнено при государственной поддержке технологической научной программы Физико-технического института им. А.Ф. Иоффе.

Экспериментальные исследования были проведены с помощью научно-технической базы ЦКПНО ФГБОУ ВО „ВГУ““

\section{Список литературы}

[1] M. Naddaf, M. Saad. J. Mater. Sci. Mater. Electron., 24, 2254 (2013).

[2] G. Flamand, J. Poortmans. Phys. Status Solidi A, 202, 1611 (2005).

[3] A.I. Belogorokhov, S.A. Gavrilov, I.A. Belogorokhov, A.A. Tikhomirov. Semiconductors, 39, 243 (2005).

[4] P. Schmuki, D.J. Lockwood, H.J. Labbé, J.W. Fraser. Appl. Phys. Lett., 69, 1620 (1996).

[5] A. Dyadenchuk. Int. J. Mod. Commun. Technol. Res., 2, 5 (2014).

[6] Д.Н. Горячев, О.М. Сресели. ФТП, 31, 1383 (1997).

[7] Y.A. Bioud, A. Boucherif, A. Belarouci, E. Paradis, D. Drouin, R. Arès. Nanoscale Res. Lett., 11, 446 (2016).

[8] A. Lebib, E. Ben Amara, L. Beji. J. Luminesc, 188, 337 (2017).

[9] A.S. Len'shin, V.M. Kashkarov, P.V. Seredin, B.L. Agapov, D.A. Minakov, V.N. Tsipenyuk. Tech. Phys., 59, 224 (2014).

[10] A.S. Len'shin, V.M. Kashkarov, V.N. Tsipenyuk, P.V. Seredin, B.L. Agapov, D.A. Minakov. Techn. Phys., 58, 284 (2013).

[11] А.С. Леньшин, В.М. Кашкаров, П.В. Середин, Д.А. Минаков, Э.П. Домашевская. ЖТФ, 85, 151 (2015).

[12] E.P. Domashevskaya, P.V. Seredin, A.N. Lukin, L.A. Bityutskaya, M.V. Grechkina, I.N. Arsentyev. Surf. Interface Anal., 38, 828 (2006).

[13] P.V. Seredin, A.V. Glotov, A.S. Lenshin, I.N. Arsentyev, D.A. Vinokurov, T. Prutskij. Semiconductors, 48, 21 (2014).

[14] R. Bernal Correa, J. Montes Monsalve, A. Pulzara Mora, M. López López, A. Cruz Orea, J.A. Cardona. Superf. Vacìo, 27, 102 (2014).

[15] N.K. Ali, M.R. Hashim, A.A. Aziz, H.A. Hassan, J. Ismail. Electrochem. Solid-State Lett., 12, K9 (2009).

[16] Paul M. Amirtharaj, David G. Seiler. Optical Properties of Semiconductors. Handbook Opt. V. II Devices Meas. Prop. Second Ed. 2nd edn (McGraw-Hill, 1995).

[17] S. Adachi. Properties of semiconductor alloys: group-IV, III$V$ and II-VI semiconductors (Chichester, U.K., Wiley, 2009).

[18] P.V. Seredin, A.V. Glotov, E.P. Domashevskaya, I.N. Arsentyev, D.A. Vinokurov, I.S. Tarasov. Phys. B: Condens. Matter, 405, 4607 (2010).

[19] P.V. Seredin, A.V. Glotov, E.P. Domashevskaya, I.N. Arsentyev, D.A. Vinokurov, I.S. Tarasov. Phys. B: Condens. Matter, 405, 2694 (2010). 
[20] V.A. Volodin, M.D. Efremov, V.Y. Prints, V.V. Preobrazhenskii, B.R. Semyagin, A.O. Govorov. J. Exper. Theor. Phys. Lett., 66, 47 (1997).

[21] P.V. Seredin, A.S. Lenshin, V.M. Kashkarov, A.N. Lukin, I.N. Arsentiev, A.D. Bondarev. Mater. Sci. Semicond. Process., 39, 551 (2015).

[22] P.V. Seredin, V.M. Kashkarov, I.N. Arsentyev, A.D. Bondarev, I.S. Tarasov. Phys. B: Condens. Matter, 495, 54 (2016).

[23] P.V. Seredin, A.S. Lenshin, D.L. Goloshchapov, A.N. Lukin, I.N. Arsentyev, A.D. Bondarev. Semiconductors, 49, 915 (2015).

[24] Ю.И. Уханов. Оптические свойства полупроводников (М., Наука, 1977).

[25] J. Tauc. Prog. Semicond. (Heywood, London), 9, 87 (1965).

Редактор Г.А. Оганесян

\section{Influence of electric-chemical etching modes on morphology, structural and optical properties of porous gallium arsenide}

P.V. Seredin ${ }^{1}$, A.S. Lenshin ${ }^{1}$, A.V. Fedyukin ${ }^{1}$, D.L. Goloshchapov ${ }^{1}$, A.N. Lukin ${ }^{1}$,

I.N. Arsentyev ${ }^{2}$, A.V. Zhabotinsky ${ }^{2}$

${ }^{1}$ Voronezh State University, 394006 Voronezh, Russia

${ }^{2}$ loffe Institute,

194021 St. Petersburg, Russia

Abstract Using of $X$-ray diffraction, SEM, IR and UV spectroscopy, the properties of porous GaAs samples obtained by means of the electrochemical etching of single-crystal $n$-GaAs $(100)$ were studied. It was shown that by selecting the electrolyte composition and etching conditions we can obtain samples of porous GaAs with varying degrees of porosity and pore size (nano/micro) as well as with a different type of a sample surface. The etching of $n$-GaAs $(100)$ under the selected conditions does not lead to the orientation of the porous layer crystals changing relative to the orientation of the single-crystal GaAs substrate (100). It leads to a decrease in the half-width of the diffraction reflexes in comparison with the initial plate, to splitting of the phonon modes in IR spectra and also changes in the optical properties in the UV range. 